\title{
Hyperkinetic Children: \\ Early Indicators \\ of Potential School Failure
}

\author{
Jules Schrager, M.S.W.* \\ Janet Lindy, Ph.D.
}

\begin{abstract}
Hyperkinetic children are identified as a "population-atrisk" upon admission to kindergarten. The etiology of hyperkinetic behavio is controversial. "Organic driveness," "hyperkinetic behavior disorder," "postencephalitic behavior," "brain damage with behavioral and conceptual deficit," "Strauss syndrome," have all been used to label essentially similar symptom constellations. Bypassing the area of controversy, a study is reported that demonstrates that children who were identified as "hyperkinetic" (using behavioral criteria developed in an earlier study) were (1) absent from school more frequently, and (2) did remarkably less well on standardized tests of school readiness than their peers rated "nonhyperkinetic." The implications are discussed and suggestions made for the development of intervention programs.
\end{abstract}

Referral of a child to one of the helping agencies often occurs at a point far beyond the time when the need for service has become explicit. By the time referral occurs, the problem has become extensive as well as acute; the disorder resonating within the family and community social systems, requiring that the worker engage numbers of persons to mediate between the child's needs and those of the significant others in his life-space. A good deal of activity is then required to disengage the members of the family from one another in order to be able to see the child and his needs, and to separate these from the needs of others. The literature in the field amply attests to the importance of early identification in order to assure the delivery of effective service.

A step beyond the concept of early identification of the individual case is embodied in the notion of "populations-at-risk." This orientation suggests that, given certain noxious conditions, a population is likely to respond by developing certain pathological states. Young children, poorly nourished, living in tenements whose walls are painted with products containing lead are at risk with respect to lead poisoning; primiparous young

${ }^{*}$ Mr. Schrager is Director Department of Social Work, University of Michigan Hospital, and Associate Professor, School of Social Work, University of Michigan. Mrs. Lindy was a doctoral candidate at the University of Michigan. An earlier version of this paper was presented at the Annual Meeting of the American Orthopsychiatric Association, March, 1967 . 
women are at risk with respect to premature delivery and its attendant hazards, and so on. Social workers in childserving agencies are acutely aware of many of the prodromal signs that, unattended, result in the later need for extensive remedial or reparative services.

The material that follows reports a study to identify a population-atrisk, i.e., hyperkinetic children; describes some of their characteristics; points up some of the problems which appear with school entry; and suggests some dimensions for anticipatory guidance programs.

A child's first admission to school, sometimes oversentimentalized, does represent one of childhood's important milestones. Henceforth, he will be separated from his family at designated times and exposed to the values and expectations of society as they are purveyed by the school system. His conduct and his capacity will be evaluated by a societal agent, the teacher, and, to many parents this will be construed also as an appraisal of their effectiveness as parents. For most, this new experience is readily accepted and an uneventful and gratifying school career is launched. For some, the kindergarten year is the beginning of a school career that will be fraught with frustration and failure. Hyperkinetic children seem to contribute heavily to this latter group. These are children who will be observed by their teachers to be fidgety, restless, easily frustrated, hard to manage, and unable to sit' quietly. In short, lacking the very skills required to achieve success in the early school experience.

The etiology of hyperkinetic behavior has generated considerable controversy (Schrager, Lindy, Harrison, and McDermott, 1966a). Organic driveness, hyperkinetic behavior disorder, postencephalitic behavior, and "Strauss syndrome" are a few of the titles which have been assigned to very similar symptom complexes. Cruickshank (1961) underscores this lack of congruence:

"If such a child did exist, he might, under various circumstances, be classified as brain injured or as one demonstrating several signs of brain injury. He might be emotionally disturbed; having a home problem; a weak ego or lack of ego integration; as lacking inner controls, requiring a rigid, controlled, structured environment; or as needing one which is warmly permissive. Such a child might be classified as a 'real boy' whose problems are ones which he will outgrow."

Although such areas of controversy loom large, it is reassuring to focus upon areas of agreement at the behavioral level. (Schrager et al. 1966b). Lourie (1963) remarks:

We make this diagnosis (of "hyperkinetic child") in the waiting room usually. While the youngster is poking over the shoulders of the secretary, pulling the paper out of the typewriter, the mother is saying helplessly, "Now Johnny, you know you shouldn't do that."

Others have registered notably similar impressions. Despite semantic and conceptual disparities related to the etiology, course, or preferred choice of treatment, there is agreement concerning the troublesome quality of hyperkinetic behavior whenever it is observed. 
Using behavioral attributes as a focus, a project to identify hyperkinetic children in the public schools was undertaken here in Ann Arbor. In the pilot stage nearly 500 kindergarten children in six schools, a cross-section of the population in the area, were screened to select out those kindergarteners who were hyperkinetic. Questions as to whether the behavior was a product of an insult to the brain, disturbed family dynamics, genetic composition, social pressure, or any admixture of these, were bypassed. An interdisciplinary study was conducted to decide which specific behaviors were most commonly considered characteristic of the hyperkinetic child. Pediatricians, teachers, psychologists, psychiatrists, and social workers who were surveyed agreed upon six behavioral attributes. These were: being fidgety and restless, inattentive, hard to manage, unable to sit still, pay attention, or take frustration. Those kindergarten children who were observed by their teachers and their parents to exhibit these behavioral attributes will be discussed. They were selected by the use of a 44 item checklist in which the six key behaviors were embedded. It was distributed to parents at the time of admission to school, and four weeks later to teachers. Teacher's ratings were individually normalized to minimize the effect of differences in rating styles. Ratings on a composite of the six key behaviors were then tallied for each child. The result was an index of hyperkinetic behavior, with all children being placed on a theoretical continuum from "nonhyperkinetic" to "high hyperkinetic."

Patently the six typical behaviors of hyperkinetic children could be considered incompatible with school demands. As a result of their troublesome behavior, these children might be expected to elicit negative responses from teachers, and from their peers. It would not be surprising if responsively, they themselves began to have negative feelings toward school. Because of their inability to sit still and pay attention, and because of associated sensory-motor and perceptive difficulties, success with academic as well as the social aspects of school could be expected to be impaired.

Two aspects of the school experience, absenteeism and performance on "readiness tests," were examined as possible indicators of social and scholastic problems. Rate of absences was selected as an index of attitude toward school, while performance on tests was used as a measure of facility with academic tasks.

Absenteeism has been much investigated in the world of work. School absences have not been as carefully scrutinized. Generally, absence is assumed to be caused by illness. At the level of secondary education absenteeism (or truancy) seems to be characteristic of youngsters having little interest in school, regardless of their physical state of health. A poor attendance record seems also to be a prodromal sign of the school dropout. Absenteeism then has a psychosocial as well as a physical aspect. Later disaffection with school may have its precursor in the poor attendance records of children who find school a less than gratifying experience. 
It has been documented that hyperkinetic behavior is difficult to manage, and that the hyperkinetic child taxes the patience of the most understanding teacher. He may have repeated conflicts with classmates and teachers. He is often reprimanded for disturbing the classroom routine. His lack of ability to meet social demands causes him to be seen as a perpetually disruptive influence. His lack of social skills gives him little opportunity to experience praise or other positive reinforcements in school. If this is indeed the common experience, the consequence might be reflected in relatively higher rates of absences for hyperkinetic children than for other children in kindergarten.

The kindergarten year is an especially opportune time to examine in terms of the above hypothesis. The child is not responsible for learning formal academic skills. He has no homework and no grades for academic performances. It is a period of induction into the social system of the school and emphasizes "enjoyable" types of individual and group activity. Parents exert less pressure on kindergarten children than on other schoolaged children to attend school for fear that they will miss something or fall behind in their work, and thereby fail in some subject area. A kindergartner's attendance at school then is determined by his "feeling" about the school situation. We hypothesize that kindergarten children whose school experiences were rewarding would be those who would be eager to attend school. Conversely, those children who were experiencing failure and frustration would be expected to be less eager to attend school. Thus, absence from school (without supporting evidence of physical illness), can be assumed to reflect a child's negative feeling about the school experience.

Readiness tests as an index to potential academic success require little comment since their reliability in predicting school performance (especially at the early primary level), has been documented. Two tests were employed in our study: the Metropolitan Readiness Test and the Lee-Clark Reading Readiness Test. Their use was dictated by practical considerations since they were routinely administered to all kindergarten children in most of the schools that participated in the study.

Deficits observed in the hyperkinetic kindergarten child, such as the inability to sit still and pay attention, would make even a casual observer question the readiness of such a child to begin formal academic training. Reading and writing skills rest at least in part upon a child's ability to attend to details and focus upon a given task for a reasonable period of time. One might expect, therefore that readiness (as expressed in the behavior of the hyperkinetic child) would be reflected in his inferior performance on tests which measure this capability. The nature of the tasks of which these tests are composed, recognizing similarities and differences, copying and identifying letters, and so on, might be expected to highlight the sensory-motor and conceptual difficulties in a segment of the hyperkinetic children included 
in the sample. These elements, singly or in varying combinations, should appear as an overall decrement in test results for the hyperkinetic kindergarten child.

\section{RESULTS}

Table $I$ indicates that a statistically significant relationship exists between hyperkinetic behavior and absence from school; hyperkinetic children holding a greater number of absences. The percentages in Table 2 show that 63 percent of the 107 children having low rates belong to the nonhyperkinetic group, while only 37 percent of hyperkinetic children fall into this low absence category. Conversely, comparing the 51 hyperkinetic with their nonhyperkinetic peers, 31 percent of nonhyperkinetic youngsters are observed to have high absence rates while 69 percent of the hyperkinetic group are in this category.

A parsimonious explanation would be that hyperkinetic children are more frequently ill (and therefore absent) than their nonhyperkinetic peers. Table

TABLE 1

Hyperkinetic behavior and absences

\begin{tabular}{|c|c|c|c|c|c|c|c|c|}
\hline \multicolumn{9}{|c|}{ Absences } \\
\hline \multirow{2}{*}{$\begin{array}{c}\text { Criterion } \\
\text { hyperkinetic }\end{array}$} & \multirow{2}{*}{$\begin{array}{l}\text { Low } \\
0-5\end{array}$} & \multirow[b]{2}{*}{$6-11$} & \multirow[b]{2}{*}{$12-17$} & \multirow[b]{2}{*}{$18-23$} & \multirow[b]{2}{*}{$24-29$} & \multicolumn{3}{|c|}{ High } \\
\hline & & & & & & $30-35$ & 36 & or more \\
\hline 1 & 6 & $12)$ & 6 & 7 & 4 & 2 & 2) & 39 \\
\hline 2 & 5 & 8 & 12 & 6 & I & $I$ & $I$ & 44 \\
\hline 3 & 10 & II & 16 & 5 & 3 & o & $2 /$ & 47 \\
\hline 4 & 3 & II & 18 & 6 & 4 & 1 & $I$ & 44 \\
\hline 5 & 4 & 12 & 16 & 6 & 3 & o & $I$ & 42 \\
\hline 6 & 2 & 17 & 13 & 8 & 3 & 2 & $I$ & 45 \\
\hline 7 & 5 & II & 6 & 1 & 11 & o & o & 40 \\
\hline \multicolumn{9}{|l|}{ nonhyperkinetic } \\
\hline 8 & 9 & $12)$ & 9 & 5 & $/ 10$ & I & 2) & 44 \\
\hline 9 & 5 & $10)$ & 8 & 8 & 5 & 2 & o & 42 \\
\hline \multirow[t]{2}{*}{10} & 2 & $7 /$ & 12 & 9 & 7 & 3 & $5)$ & 45 \\
\hline & 50 & 121 & 116 & 51 & 12 & 12 & 15 & 432 \\
\hline
\end{tabular}

$x^{2}=80.503,56 \mathrm{df}, \mathrm{p}<.05$

TABLE 2

\begin{tabular}{lrrr}
\hline \hline \multicolumn{1}{c}{ Criterion } & Absences & & \\
& Under 11 & Over 23 \\
\hline non hyperkinetic & $62(62.16 \%)$ & $16(31.37 \%)$ & 78 \\
hyperkinetic & $45(37.49 \%)$ & $35(68.63 \%$ & 78 \\
total & $107(100 \%)$ & $51(100 \%)$ & 156 \\
\hline
\end{tabular}

$\chi^{2}=9.756, \mathrm{Idf}, \mathrm{p}<.01$ 
3 tests this by correlating teacher ratings of the presence of symptoms of illness and the criterion index of hyperkinetic behavior.

There appears a notable lack of correlation between the criterion and teacher ratings for the eight signs or symptoms in this table. Three of the eight items result in negative correlation; the highest positive correlation, with the five remaining items is only 0.15 . The possibility remains that the physical symptoms are, in fact, present more often in the hyperkinetic group than in the nonhyperkinetic, but that teachers do not see them in the hyperkinetic group because these children are absent from school, the symptoms having subsided by the time they return. To test this, parent ratings (see Table 4) for the same eight signs and symptoms were tabulated.

\section{TABLE 3}

Correlation between criterion and teacher rated physical signs and symptoms (6 schools,

II teachers, 494 children)

\begin{tabular}{lr}
\hline \hline 1. Dizziness or nausea & -.08 \\
2. Head colds & .09 \\
3. Coughs & .03 \\
4. Runny nose & .15 \\
5. Vomiting & -.02 \\
7. Breathes funny & .10 \\
12. Headaches & -.04 \\
35. Tummyaches & .05
\end{tabular}

TABLE 4

Chi square values for parent ratings of "low" and "high" criterion children*

\begin{tabular}{ll}
\hline Physical signs and symptoms & Key behaviors \\
\hline 1. Dizziness or nausea & 9. Fidgets, is restless \\
$\chi^{2}=1.476,2 \mathrm{df}, \mathrm{NS}$ & $\chi^{2}=7.612,2 \mathrm{df}, \mathrm{p}<.05$ \\
2. Head colds & 10. Inattentive \\
$\chi^{2}=3.092,2 \mathrm{df}, \mathrm{NS}$ & $\chi^{2}=6.295,2 \mathrm{df}, \mathrm{p}<.01$ \\
3. Coughs & 16. Hard to manage \\
$\chi^{2}=4.638,2 \mathrm{df}, \mathrm{NS}$ & $\chi^{2}=14.390,2 \mathrm{df}, \mathrm{p}<.01$ \\
4. Runny nose & 30. Can't sit quietly \\
$\chi^{2}=1.285,2 \mathrm{df}, \mathrm{NS}$ & $\chi^{2}=20.276,2 \mathrm{df}, \mathrm{p}<.01$ \\
5. Vomiting & 37. Can't pay attention \\
$\chi^{2}=1.047,2 \mathrm{df}, \mathrm{NS}$ & $\chi^{2}=18.463,2 \mathrm{df}, \mathrm{p}<.01$ \\
7. Breathes funny & 40. Can't tolerate frustration \\
$\chi^{2}=.885,2 \mathrm{df}, \mathrm{NS}$ & $\chi^{2}=3.681,2 \mathrm{df}, \mathrm{NS}$ \\
$12 . \quad \chi^{2}=1.5668,1 \mathrm{df}, \mathrm{NS}$ & \\
35. Tummyaches & \\
$\chi^{2}=1.589,2 \mathrm{df}, \mathrm{NS}$ & \\
\hline
\end{tabular}

* Translation: I. Do parents indicate roughly the same incidence of physical signs and symptoms in their hyperkinetic children as in their nonhyperkinetic children? 2. Do parents tend to agree with teachers concerning the presence of hyperkinetic behavior in their children? 
We see that there is strong agreement between teacher ratings and parent ratings for five of the six key behaviors. In no case is a significant relationship observed to exist between the criterion and parent ratings for any of the eight physical signs of symptoms. One must conclude that something other than physical health accounts for the difference in absence rates in hyperkinetic and nonhyperkinetic children. We suggest that intrinsic satisfaction with school presents itself as a plausible explanation.

Turning to the results of readiness tests we again see a dichotomy between hyperkinetic and nonhyperkinetic children. We observe that not a single member of the nonhyperkinetic group falls into either the "low normal" or "poor risk" category on the Metropolitan, i.e., with a score under 59. However 18 of the 64 members of the hyperkinetic group fall into this low readiness category. Results obtained from the Lee-Clark confirm this observed tendency. The lower half of Table 5 shows not a single member of the nonhyperkinetic group is in the lower end of the "low average" readiness group, i.e., scores below 45. Thirteen of the 50 members of the hyperkinetic group, however, fall into this category. The opposite trend is observed when we inspect the high readiness categories.

We observed that members of the hyperkinetic group were absent from school with greater frequency than their nonhyperkinetic claassmates. The possibility arises that absence from school might be depriving hyperkinetic children of the opportunity to learn some basic skills measured by readiness tests. To test this, the relationship between readiness scores and absences was explored and these were observed to be functioning independently.

TABLE 5

Criterion and scores on the Metropolitan Readiness Test

\begin{tabular}{|c|c|c|c|c|c|c|}
\hline & \multicolumn{6}{|c|}{ Total raw score } \\
\hline Criterion & $\begin{array}{l}\text { Poor risk } \\
0-59\end{array}$ & $60-69$ & $7^{0-79}$ & $80-89$ & $90-99$ & \\
\hline \multirow{3}{*}{$\begin{array}{l}\text { nonhyperkinetic } \\
\text { hyperkinetic }\end{array}$} & 0 & 4 & 18 & 26 & 13 & 61 \\
\hline & 18 & 19 & 19 & 5 & 3 & 64 \\
\hline & 18 & 23 & 37 & 31 & 16 & 125 \\
\hline \multirow{2}{*}{\multicolumn{7}{|c|}{ Criterion and scores on the Lee-Clark Readiness Test }} \\
\hline & & & & & & \\
\hline & \multicolumn{6}{|c|}{ Total raw score } \\
\hline \multirow[t]{2}{*}{ Criterion } & Low & & & & High & \\
\hline & $25-44$ & $45-59$ & $50-54$ & $55-59$ & $60-64$ & \\
\hline \multirow{3}{*}{$\begin{array}{l}\text { nonhyperkinetic } \\
\text { hyperkinetic }\end{array}$} & 0 & 8 & 12 & 17 & 6 & 43 \\
\hline & 13 & 8 & 13 & 18 & $x$ & 50 \\
\hline & 13 & 16 & 25 & 32 & 7 & 93 \\
\hline
\end{tabular}

$\chi^{2}=20.60,4 \mathrm{df}, \mathrm{p}<.01$ 
In summary then, hyperkinetic kindergarten children were observed to have a relatively high rate of absence without evidence of poorer health than their classmates. They also exhibited poorer performance on standardized measures predicting readiness for school. Attitudes toward school as well as difficulty with school tasks could be anticipated to result in problems for hyperkinetic children. The frequency of referrals of hyperkinetic children to diagnostic and treatment centers by school personnel attests to the fact that school difficulties typify this population. Moreover, our findings suggest that the very children who need the socializing influence and skill training that the school provides may, in fact, be those who are least exposed to it, and when exposed, may least profit from their exposure. Despite the lack of precise understanding of hyperkinetic behavior, schools must nonetheless cope with it.

In this descriptive study we have shown that teachers and parents have identified a group of children who constitute a population-at-risk upon entry into school. While recognizing that the group identified is a mixed bag (in that precise etiological characteristics are obscure), it seems worthwhile to suggest that the apparent vulnerability of the group to later school failure requires that efforts be made to make passage through the early school years less eventful than might otherwise be the case.

Two strategies suggest themselves as useful in this regard. First a program of anticipatory guidance for parents that might sensitize them to the special school problems these children are likely to present. Meetings under professional leadership utilizing the group as a vehicle for: sharing concerns over school performance to anticipate the unique problems that are likely to appear as he moves through the grades into more concrete subject matter; to develop concrete new "competencies" in the management of behavior; and to foster mutual support of new efforts at coping. Second, a program of teacher consultation assisting the teacher through heightened sensitivity to develop coping techniques within the classroom that might accommodate to the needs of the hyperkinetic child. It is not assumed that programs such as these will "make the symptoms go away." It can be expected, however, that the accumulated experience of professionals in utilizing new techniques for study and evaluation might result in earlier differential use of remedial resources, and for some of the children, a more benign experience in the early school years.

\section{REFERENCES}

Cruikshank, W. et al. A teaching method for brain-injured and hyperkinetic children. Syracuse, N. Y.: Syracuse University Press, 1961.

Lourie, R. S. The contributions of child psychiatry to the pathogenesis of hyperactivity in children. Clinical Proceedings of the Children's Hospital, Sept. 1963, 9.

Schrager, J., Lindy, J., Harrison, S., \& McDermott, J. The hyperkinetic child: An overview of the issues. Iournal of the Academy Child Psychiatry, 1966, 5, 526-533.

Schrager, J., Lindy, J., Harrison, S., \& McDermott, J., The hyperkinetic child: Some consensually validated behavioral correlates. Exceptional Child, 1966, 32, 635-637. 